\title{
Impaired glucose tolerance and diabetes mellitus in a rural population in South India
}

\author{
Svati Patandin ${ }^{\mathrm{a}}$, Michiel L. Bots*a, Rajaratnam Abel ${ }^{\mathrm{b}}$, \\ Hans A. Valkenburg ${ }^{\mathrm{a}}$ \\ ${ }^{a}$ Department of Epidemiology and Biostatistics, Erasmus University Medical School, \\ P.O. Box 1738, 3000 DR Rotterdam, The Netherlands \\ ${ }^{b}$ Rural Unit for Health and Social Affairs (RUHSA), Christian Medical College and Hospital, \\ Vellore, South India
}

(Received 28 September 1993; revision received 19 January 1994; accepted 24 January 1994)

\begin{abstract}
In the present study the prevalence of impaired glucose tolerance and non-insulin dependent diabetes mellitus in a rural population in South India was assessed and its associations with body mass index and a family history of diabetes mellitus. Data were obtained from inhabitants of two villages located in the North Arcot District of Tamil Nadu. After an overnight fast, 467 randomly selected subjects, aged 40 years or over, were given $75 \mathrm{~g}$ glucose orally. After two hours the capillary glucose level was determined. The prevalence of impaired glucose tolerance $(2 \mathrm{~h}$ value $\geq 7.8 \mathrm{mmol} / \mathrm{l}$ and $<11.1 \mathrm{mmol} / \mathrm{l}$ ) was $6.6 \%$ ( 31 subjects). Non-insulin dependent diabetes mellitus ( $2 \mathrm{~h}$ value $\geq 11.1 \mathrm{mmol} / \mathrm{h}$ ) was found in 23 subjects (4.9\%). Of these, 53\% were previously unknown. Age and sex adjusted mean body mass index was significantly higher among subjects with impaired glucose tolerance compared to subjects without glucose intolerance, with a mean difference of $1.4 \mathrm{~kg} / \mathrm{m}^{2}(95 \%$ confidence interval (CI) $0.2,2.6)$. A positive family history of diabetes was non-significantly higher in subjects with impaired glucose tolerance. Subjects with non-insulin-dependent diabetes mellitus had a higher mean body mass index compared to subjects with normal glucose levels with a mean difference of $1.9 \mathrm{~kg} / \mathrm{m}^{2}(95 \% \mathrm{CI} 0.5,3.3)$. A positive family history of diabetes was more common among diabetics with a difference of $20 \%(95 \% \mathrm{CI} 10,30)$. Our findings suggest that in a considerable proportion (11.5\%) of the rural South Indian population aged 40 years or over glucose intolerance is present. These results may indicate that apart from other important causes of morbidity and mortality, a substantial proportion of the rural Indian population will suffer from cardiovascular morbidity and mortality in the near future.
\end{abstract}

Keywords: Diabetes mellitus; Impaired glucose tolerance; Rural population; Prevalence; Tamil Nadu; South India

\section{Introduction}

- Corresponding author, Tel.: 3110 4087489; Fax: 3110 4087494.

The prevalence of impaired glucose tolerance and non-insulin-dependent diabetes mellitus varies 
considerably across populations [1-3]. Studies among migrant Indians throughout the world [4-10] have shown a higher prevalence of diabetes mellitus compared to the population residing in the Indian sub-continent and compared to that found in other racial groups in the host country [11]. In 1978, the Indian Council of Medical Research (ICMR) study reported a higher prevalence of diabetes mellitus in urban than in rural populations [12]. Recent studies in urban populations in Kundremukh, South India [13] and in Darya Ganj, New-Delhi [14] show that a relatively high prevalence observed in migrant Indians is now also found in India, suggesting an ethnic susceptibility to diabetes which is revealed with exposure to environmental factors [11]. Population-based studies on the prevalence of non-insulin-dependent diabetes mellitus (NIDDM) and particularly of impaired glucose tolerance (IGT) in rural parts of India, where the majority of the population live, are rarely documented.

Therefore we report the findings of a population-based survey in a rural area of South India, in which the prevalence of impaired glucose tolerance and non-insulin-dependent diabetes mellitus, was assessed according to the 1985 WHO standards [1] and its associations with body mass index and family history of diabetes mellitus.

\section{Materials and methods}

The participants came from two villages of the KV Kuppam block (104000 inhabitants) located in North Arcot District of Tamil Nadu. Both villages consisted of 450 families each with a total population of 5000 inhabitants. Each family was registered at the Rural Unit for Health and Social Affairs (RUHSA). This registration provided information on name, age, gender and address. A population sample was obtained by visiting every third family, for which the information came from the registration used at the RUHSA. Subjects aged 40 years or over were eligible for the study. They were informed and motivated to participate in the study by Family Care Volunteers and Rural Community Officers, who are both representatives of the rural community. All participants were visited the night before. The objective of the survey and the importance of an overnight fast was explained to them in their own language (Tamil). The study was carried out from September 1990 to December 1990.

\subsection{Measurements}

At 06:00 $\mathrm{h}$ participants were given a monohydrate glucose solution of $75 \mathrm{~g}$ in $250 \mathrm{ml}$ of water after an overnight fast and were requested to wait $2 \mathrm{~h}$. Their 2-h capillary blood glucose level was determined using a Reflolux II $\mathbf{M}$ glucometer (Boehringer Mannheim B.V., Germany) [15]. A short questionnaire was completed on age, gender, occupation, income and family history of diabetes. Height and weight were measured with a balance stadiometer. These measurements were done by the same observer. Body mass index (BMI, $\mathrm{kg} / \mathrm{m}^{2}$ ), as weight to height squared, was calculated. Although subjects who were receiving oral anti-diabetic treatment were not submitted to an oral glucose load, they were included in the assessment of the prevalence of diabetes mellitus. None of them used insulin treatment.

\subsection{Definitions}

Glucose tolerance was defined according to the 1985 WHO criteria using a $2 \mathrm{~h}$ post-load capillary blood sample [1]. Subjects with a $2 \mathrm{~h}$ glucose concentration of $11.1 \mathrm{mmol} / 1$ or over were classified as diabetes mellitus. Subjects with a $2 \mathrm{~h}$ value ranging from 7.8 to $11.1 \mathrm{mmol} / 1$ were categorized as subjects with impaired glucose tolerance. Subjects with a blood glucose level lower than $7.8 \mathrm{mmol} / \mathrm{l}$ were classified as subjects with normal glucose tolerance. The capillary blood glucose levels measured with the Reflolux II $\mathrm{M}$ method have been reported to show a satisfactory association with capillary glucose levels measured with the classical hexokinase methods (correlation coefficients $>0.99$ ). In these studies the regression line between the glucose levels measured by the two methods was characterized by $y=1.06 x+-1.41(\mathrm{mg} / \mathrm{dl})$ and $y=0.96 x+7.8$ (mg/dl), respectively $[16,17]$.

The population has been divided into quartiles according to their body mass index. The upper quartile of the BMI of the study population $(\geq 21.97$ $\mathrm{kg} / \mathrm{m}^{2}$ ) was taken as a cut-off value to characterize subjects with an increased body weight. The con- 
ventional definition of overweight (BMI > 25 $\mathrm{kg} / \mathrm{m}^{2}$ ) was not used, since there was a very limited number of subjects fulfilling this criteria with impaired glucose tolerance $(n=7)$ and with diabetes mellitus $(n=3)$ in the studied population. A positive family history of diabetes was considered present when a first degree relative (parents, siblings and children) was treated for diabetes mellitus.

\subsection{Data analysis}

The mean levels and proportions of several risk indicators of subjects with impaired glucose tolerance and non-insulin-dependent diabetes mellitus were compared to those of subjects with a normal glucose tolerance. The latter group was considered as a reference group. Multiple linear regression analysis was used for analysis of differences across groups, adjusted for age and gender [18]. The odds ratio was calculated using a multiple logistic regression analysis to assess the strength of the association between the upper quartile of BMI, family history and glucose intolerance, adjusted for age and gender. Results are presented with a 95\% confidence interval.

Four hundred and ninety subjects were asked and participated in the study. The response rate was $100 \%$, resulting in a fairly representative study sample for the Indians living in that rural area. Twenty three subjects were excluded due to a non-fasting state, a meal after glucose loading and not returning after $2 \mathrm{~h}$ for a blood sample. Because all participants were 40 years or over, and known diabetics used no insulin treatment, it is most likely that they all may be considered as having non-insulindependent diabetes mellitus.

\section{Results}

Among the 467 participants 192 were men and 275 were women. The prevalence of impaired glucose tolerance was $6.6 \%$ ( 18 men and 13 women). Non-insulin-dependent diabetes mellitus was observed in 23 subjects $(4.9 \%)$, of which 13 were men (Table 1). Of the 23 subjects with non-insulindependent diabetes mellitus, $11(2.3 \%)$ were known diabetics and were using oral anti-diabetic drugs at the time of the study. The prevalence of impaired glucose tolerance and non-insulin-dependent diabetes mellitus increased with age in both men and women (Table 1). Impaired glucose tolerance was more common in men than in women, $9.4 \%$ and $4.7 \%$, respectively. A similar finding was observed for non-insulin-dependent diabetes mellitus: $6.8 \%$ and $3.6 \%$, respectively. The difference in prevalence between men and women could not be attributed to differences in body mass index or to differences in the prevalence of overweight subjects.

Compared to controls, subjects with impaired glucose tolerance were older, had a higher mean body mass index and among them were more men and subjects with a positive family history of diabetes mellitus (Table 2). The differences in mean body mass index across groups remained statistically significant when differences in age and gender were

Table 1

Prevalence of impaired glucose tolerance and non-insulin-dependent diabetes mellitus in a rural population aged 40 years or over in South India. Results are presented by age and gender

\begin{tabular}{|c|c|c|c|c|c|}
\hline & Normal & IGT & $95 \% \mathrm{CI}$ & NIDDM & $95 \% \mathrm{CI}$ \\
\hline \multicolumn{6}{|l|}{$\overline{M e n}$} \\
\hline $40-59$ years & $111(86.7)$ & $9(7.0)$ & $2.6-11.4$ & $8(6.3)$ & $2.1-10.5$ \\
\hline$\geq 60$ years & $50(78.1)$ & $9(14.1)$ & $5.6-22.6$ & $5(7.8)$ & $1.2-14.4$ \\
\hline All & $161(83.9)$ & $18(9.4)$ & $5.3-13.5$ & $13(6.8)$ & $3.2-10.3$ \\
\hline \multicolumn{6}{|l|}{ Women } \\
\hline $40-59$ years & $185(93.0)$ & $7(3.5)$ & $1.0-6.1$ & $7(3.5)$ & $1.0-6.1$ \\
\hline$\geq 60$ years & $67(88.2)$ & $6(7.9)$ & $1.8-14.0$ & $3(3.9)$ & $0.0-8.3$ \\
\hline All & $252(91.6)$ & $13(4.7)$ & $2.2-7.2$ & $10(3.6)$ & $1.4-5.9$ \\
\hline Total & $413(88.4)$ & $31(6.6)$ & $4.4-8.9$ & $23(4.9)$ & $2.9-6.9$ \\
\hline
\end{tabular}

Values are numbers with percentage between parentheses. 
Table 2

General characteristics of the studied population by groups of glucose intolerance, and its association with body mass index and a positive family history of diabetes mellitus

\begin{tabular}{|c|c|c|c|c|c|}
\hline & Normal & IGT & NIDDM & $\begin{array}{l}\text { Adjusted mean difference } \\
\text { between IGT and } \\
\text { normal }^{\text {a }}\end{array}$ & $\begin{array}{l}\text { Adjusted mean difference } \\
\text { between NIDDM and } \\
\text { normal }^{\mathrm{a}}\end{array}$ \\
\hline Number & 413 & 31 & 23 & & \\
\hline Age (years) & $53(1)$ & $57(2)$ & $57(3)$ & & \\
\hline Male $(\%)$ & $39 \%$ & $58 \%$ & $57 \%$ & & \\
\hline BMI $\left(\mathrm{kg} / \mathrm{m}^{2}\right)$ & $19.4(0.2)$ & $20.5(0.9)$ & $21.4(0.9)$ & $1.4[0.2,2.6], P=0.03$ & $1.9[0.5,3.3], P=0.01$ \\
\hline $\begin{array}{l}\text { Upper quartile of } \\
\text { BMI }^{\mathrm{b}}(\%)\end{array}$ & $22 \%$ & $48 \%$ & $48 \%$ & $27 \%[11,43], P<0.01$ & $25 \%[7,43], P=0.01$ \\
\hline $\begin{array}{c}\text { Positive family } \\
\text { history (\%) }\end{array}$ & $5 \%$ & $13 \%$ & $25 \%$ & $8 \%[-1,17], P=0.08$ & $20 \%[10,30], P=0.03$ \\
\hline
\end{tabular}

Values are percentages or means with $\mathrm{S}$.E. between parentheses.

${ }^{4}$ Results adjusted for age and sex, presented with a $95 \% \mathrm{CI}$ and $P$-value.

bUpper quartile $(\geq 21.97)$ of the distribution of the BMI.

taken into account $(P=0.03$, Table 2$)$. Results from logistic regression analysis indicated that among subjects with a body mass index in the upper quartile, impaired glucose tolerance was 2.6 times more likely than among subjects with a BMI below the upper quartile; the odds ratio was $2.6(95 \% \mathrm{CI}$ $1.2,5.9)(P=0.01)$. This finding was independent of age, gender and family history.

With respect to subjects with non-insulindependent diabetes mellitus, similar findings were observed. Compared to controls, they were slightly older, had a higher body mass index, and among them were more men and more subjects with a positive family history of diabetes mellitus. The observed association between body mass index and family history remained statistically significant after adjustments were made for age and gender, $P=0.01$ and $P<0.01$, respectively (Table 2). The age and gender adjusted odds ratio for subjects with a BMI in the upper quartile having diabetes mellitus compared to those with a BMI below the upper quartile was $2.6(95 \% \mathrm{CI} 1.0,6.7)(P=0.05)$. Additional adjustment for family history reduced the magnitude of the observed association; the odds ratio was 1.9 $(95 \%$ CI $0.7,5.3)(P=0.34)$.

\section{Discussion}

In our population-based study among 467 subjects, aged 40 years or over, living in a rural area in South India the prevalence of impaired glucose tolerance and non-insulin-dependent diabetes mellitus was $6.6 \%$ and $4.9 \%$, respectively. The prevalence of glucose intolerance increased with age. Furthermore, glucose intolerance was more common in men than in women. Increasing body mass index was significantly, and independently from age and gender, associated with impaired glucose tolerance and non-insulin-dependent diabetes mellitus. A positive family history of diabetes was significantly more common among those with non-insulindependent diabetes mellitus.

Because of feasibility reasons only a $2 \mathrm{~h}$ glucose value was used to define the status of glucose intolerance. This approach is less sensitive in detecting glucose intolerance than the standard WHO glucose tolerance test. This may have underestimated the actual prevalence of impaired glucose tolerance and non-insulin-dependent diabetes mellitus in this study and may have reduced the magnitude of the associations with body mass index and a positive family history. However, since the reproducibility of the oral glucose tolerance test is limited [19], it is not likely that the results would greatly differ if a standard WHO glucose tolerance test was used.

Several studies in India have been performed on the prevalence of diabetes mellitus [12-14,20-22]. Some of the published studies on the prevalence of diabetes mellitus and impaired glucose tolerance are summarized in Table 3. The Kundremukh and Darya Ganj surveys, both urban areas, reported a 
Table 3

Prevalence of IGT and NIDDM in India: results of several studies

\begin{tabular}{|c|c|c|c|c|c|c|c|}
\hline Ref. & Year & Location & Population & $\begin{array}{l}\text { Diagnostic } \\
\text { criteriat }\end{array}$ & Age & $\begin{array}{l}\text { Prevalence } \\
\text { NIDDM } \\
(\%)\end{array}$ & $\begin{array}{l}\text { Prevalence } \\
\text { IGT }(\%)\end{array}$ \\
\hline 12 & 1978 & $\begin{array}{l}\text { Multicentre } \\
\text { Ahmedabad }\end{array}$ & $\begin{array}{l}\text { Urban } \\
\text { Urban }\end{array}$ & a & $\begin{array}{l}>15 \\
\geq 40\end{array}$ & $\begin{array}{l}3.0 \\
8.3\end{array}$ & - \\
\hline 12 & 1978 & $\begin{array}{l}\text { Multicentre } \\
\text { Ahmedabad }\end{array}$ & $\begin{array}{l}\text { Rural } \\
\text { Rural } \\
\text { Urban and rural }\end{array}$ & $\mathbf{a}$ & $\begin{array}{l}>15 \\
\geq 40 \\
>15 \\
\geq 40\end{array}$ & $\begin{array}{l}1.3 \\
3.0 \\
2.2 \\
2.8\end{array}$ & $\begin{array}{l}- \\
- \\
-\end{array}$ \\
\hline 13 & 1986 & Darya Ganj* & Urban & b & $\begin{array}{l}\text { All } \\
\geq 40\end{array}$ & $\begin{array}{l}3.1 \\
9.1\end{array}$ & - \\
\hline 21 & 1986 & Bhadran & Rural & c & $>10$ & 3.8 & 0.33 \\
\hline 22 & 1987 & Bardoli & Urban and rural & c & All & 4.4 & 0.37 \\
\hline 12 & 1988 & Kundremukh & Urban & $\mathrm{d}$ & $\begin{array}{l}>20 \\
\geq 40 \\
\geq 45\end{array}$ & $\begin{array}{r}5.0 \\
21.0 \\
28.6\end{array}$ & $\begin{array}{l}2.0 \\
- \\
5.2\end{array}$ \\
\hline 20 & 1989 & This study & $\begin{array}{l}\text { Urban } \\
\text { Rural } \\
\text { Urban and rural } \\
\text { Rural }\end{array}$ & $b$ & $\begin{array}{l}\text { All } \\
\text { All } \\
\geq 40 \\
\geq 40\end{array}$ & $\begin{array}{l}1.5 \\
1.9 \\
6.1 \\
4.9\end{array}$ & $\frac{-}{-}$ \\
\hline
\end{tabular}

* \% prevalence of known diabetes mellitus.

$\dagger$ a, Standard oral glucose tolerance test [12]. A $40 \mathrm{~g}$ glucose load per $\mathrm{m}^{2}$ body surface area was given and then fasting, 1, 2 and $3 \mathrm{~h}$ post load blood glucose samples were taken; b, by questionnaire; c, oral glucose tolerance test, WHO criteria 1980 [20,21]; d. WHO 1985 [1]. $2 \mathrm{~h}$ post load blood glucose 7.8-11.1 $\mathrm{mmol} / \mathrm{h}$ for $\mathrm{IGT}$ and $\geq 11.1 \mathrm{mmol} / \mathrm{l}$ for NIDDM.

prevalence of non-insulin-dependent diabetes mellitus in subjects of 40 years or over of $21 \%$ and $9.1 \%$, respectively $[13,14]$. In the Darya Ganj survey only the prevalence of known diabetes mellitus was assessed [14]. More recently, the Eluru survey in 1989 performed in a town in a rural population found a prevalence of known diabetes of $6.1 \%$ in subjects aged 40 years or over [20]. Across these studies considerable differences exist in the definition and methods used to assess glucose intolerance, in selection of populations and in areas, which make comparisons difficult. Our finding of a prevalence of non-insulin-dependent diabetes mellitus of $4.9 \%$ in subjects aged 40 years or over living in a rural area, is similar to the results observed in other studies.

We are not aware of any study that has tried to assess the prevalence of impaired glucose tolerance among a rural population in South India according to the 1985 WHO criteria. Of the participants in our study a considerable proportion, $6.6 \%$, was classified as having impaired glucose tolerance. Previous studies in South India have indicated that these individuals are at high risk of developing diabetes mellitus [13,23]. This indicates that a considerable part of the rural population of South India may be burdened by morbidity from retinal, renal and arterial diseases associated with glucose intolerance in the future $[24,25]$.

In several studies an increased body mass index has been associated with the development of glucose intolerance and hyperinsulinemia [3,26]. Overweight is the best recognized risk factor for non-insulindependent diabetes mellitus and the duration of previous overweight is even more important than current overweight [27]. Furthermore, results from studies have indicated that familial aggregation was high among Indian diabetics and that there was a high prevalence of diabetes among children who had one or two diabetic parents [13,23,28-30]. Our results are in accordance with these findings.

In conclusion, our data suggest that in $11.5 \%$ of the rural population of South India aged 40 years or over, glucose intolerance is present. Furthermore, 
in an Indian population glucose intolerance also appears to be associated with an increased body mass index and a positive family history of diabetes. Our findings point out that, apart from other important causes of disease and life-expectancy, a considerable proportion of the rural Indian population may be burdened by cardiovascular morbidity and mortality in the future, which may have a dramatic inpact on the Indian public health services.

\section{Acknowledgements}

We acknowledge the efforts of Mr. Solomon Victor, who helped us enormously to perform the fieldwork. We are very greatful to Ms. Rona Schweitz for her cooperation and participation in the data acquisition during this study. We also thank Mr. Ing. A.M. de Bruijn, whose efforts in arranging the diabetes diagnostics were limitless. The diabetes diagnostics were kindly supplied by Boehringer Mannheim B.V. Almere, The Netherlands.

\section{References}

1 WHO Expert Committee on Diabetes Mellitus (1985) Technical Report Series 727, WHO, Geneva.

2 Jarrett, R.J. (1989) Epidemiological public health aspects of non-insulin-dependent diabetes mellitus. Epidemiol. Rev. 11, 151-171.

3 Zimmet, P., Finch, C. and Dowse, G. (1990) The epidemiology of diabetes mellitus. In: K.G.M.M. Alberti and L.P. Krall (Eds.), Diabetes Annual, Vol. 5. Elsevier, Amsterdam, pp. 1-21.

4 Ramaiya, K.L., Swai, A.B.M., McLarty, D.G. and Alberti, K.G.M.M. (1991) Impaired glucose tolerance and diabetes mellitus in hindu Indian immigrants in Dar es Salaam. Diabet. Med. 8, 738-744.

5 Zimmet, P., Taylor, R., Ram, P. et al. (1983) Prevalence of diabetes and impaired glucose tolerance in the biracial (Melanesian and Indian) population of Fiji: A rural urban comparison. Am. J. Epidemiol. 118, 673-688.

6 Dowse, G.K., Gareeboo, H., Zimmet. P.Z. et al. (1990) The high prevalence of non-insulin-dependent diabetes and impaired glucose tolerance in Indian, Creole and Chinese Mauritians. Diabetes 39, 390-396.

7 Mather, H.M. and Keen, H. (1985) The Southhall diabetes survey: prevalence of known diabetes in Asians and Europeans. Br. Med. J. 291, 1081-1084.

8 Simmons, D., Williams, D.R.R. and Powell, M.J. (1989) Prevalence of diabetes in a predominantly Asian community: preliminary findings of the Coventry diabetes study. Br. Med. J. 298, 18-21.

9 Omar, M.A.K., Seedat, M.A., Dyer, R.B., Rajput, M.C.,
Motala, A.A. and Joubert, S.M. (1985) The prevalence of diabetes mellitus in a large group of Indians. S. Afr. Med. J. 67, 924-926.

10 Beckles, G.L.A, Miller, G.J., Kirkwood, B.R., Alexis, S.D., Carson, D.C. and Byam, N.T.A. (1986) High total and cardiovascular mortality in adults of Indian descent in Trinidad unexplained by major coronary risk factors. Lancet i, 1298-1300.

11 Ramaiya, K.L., Kodali, V.R.R. and Alberti, K.G.M.M. (1990) Epidemiology of Asians of the Indian Subcontinent. Diabetes Metab. Rev. 6, 125-146.

12 Gupta, O.P., Joshi, M.H. and Dave, S.K. (1978) Prevalence of diabetes in India. Adv. Metab. Disorders 9, 147-165.

13 Ramachandran, A., Jali, M.V., Mohan, V., Snehalatha, C. and Viswanathan, M. (1986) High prevalence of diabetes in an urban population in South India. Br. Med. J. 297, 587-590.

14 Varma, N.P.S., Mehta, S.P., Madhu, S.V., Mather, H.M. and Keen, H. (1986) Prevalence of known diabetes in an urban Indian environment: the Darya Ganj diabetes survey. Br. Med. J. 293, 423-424.

15 Operating instructions REFLOLUX II M. Boehringer Mannheim, Germany.

16 Koschinsky, T., Schlebusch, H., Sorger, M., Robert, J.J. and Willamowski, K.D. (1987) Reflolux II. Ein neues Blutglucosemeßgerät mit erweitertem Meßbereich. Laboratoriums Medizin 11, 97-100.

17 Schlebusch, H., Sorger, M., Schnieder, Ch. and Koberstein, R. (1984) Ein neues gerät zur blutzucker-selbstkontrolle. Laboratoriums Medizin 8, 245-247.

18 BMDP Statistical Software (1985) University California Press, Berkeley, CA.

19 Feskens, E.J.M., Bowles, C.H. and Kromhout, D. (1991) Intra- and interindividual variability of glucose tolerance in an elderly population. J. Clin. Epidemiol. 44, 947-953.

20 Rao, P.V., Ushabala, P., Seshiah, V., Ahuja, M.M.S. and Mather, H.M. (1989) The Eluru survey: prevalence of known diabetes in a rural Indian population. Diabetes Res. Clin. Pract. 7, 29-31.

21 Patel, J.C. (1986) Prevalence of hypertension and diabetes mellitus in a rural village. J. Diabetic Assoc. India 26, 68-73.

22 lyer, S.R., Chauhan, R.B., Khandwala, R.M. and Shah, P.C. (1987) Diabetes mellitus in and around Bardoli. J. Diabetic Assoc. India 27, 11-14.

23 Ramachandran, A., Shehelata, C., Naik, R.A.S., Mohan, V., Shobana, R. and Viswanathan, M. (1986) Significance of impaired glucose tolerance in an Asian Indian population: a follow-up study. Diabetes Res. Clin. Pract. 2, 173-178.

24 Nathan, D.M. (1993) Long term complications of diabetes mellitus. N. Engl. J. Med. 328, 1676-1685.

25 Donahue, R.P. and Orchard, T.J. (1992) Diabetes mellitus and macrovascular complications. An epidemiological perspective. Diabetes Care 15, 1141-1155.

26 Mykkänen, L., Laakso, M., Uusitupa, M. and Pyörälä, K. 
(1990) Prevalence of diabetes and impaired glucose tolerance in elderly subjects and their association with obesity and family history of diabetes. Diabetes Care 13, 10991105.

27 Barrett-Connor, E. (1989) Epidemiology, obesity, and non-insulin-dependent diabetes mellitus. Epidemiol. Rev, 11, 172-181.

28 Mohan, V., Sharp, P.S., Aber, V.R., Mather, H.M. and Kohner, E.M. (1986) Family histories of Asian and European non-insulin-dependent diabetic patients. Practical Diabetes 3, 254-256.
29 Viswanathan, M., Mohan, V., Snehalatha, C. and Ramachandran, A. (1986) High prevalence of type 2 (noninsulin-dependent) diabetes among offspring of conjugal type 2 diabetic parents in India. Diabetologia 28 . 907-910.

30 Ramachandran, A., Mohan, V., Snehalatha, C. and Viswanathan, M. (1988) Prevalence of non-insulin-dependent diabetes mellitus in Asian Indian families with a single diabetic parent. Diabetes Res. Clin. Pract. 4, 241-245. 